\title{
Analisis Volatilitas Harga Eceran Komoditas Beberapa Pangan Utama di Kota Manado Menggunakan Model ARCH
}

\author{
Wanri Naiggolana, Nelson Nainggolana*, Hanny A.H. Komaliga*
}

aJurusan Matematika, FMIPA, Unsrat, Manado

\begin{tabular}{l} 
K A T A K U N C I \\
\hline Cabai Rawit Merah \\
Tomat Apel \\
Volatilitas \\
ARCH/GARCH
\end{tabular}

\begin{abstract}
A B S T R A K
Konsumsi bahan pangan utama seperti cabai rawit merah dan tomat apel selalu menjadi sorotan bagi kalangan masyarakat, hal ini disebabkan oleh harga yang tidak tetap dan selalu berfluktuasi pada setiap periode. Besaran perubahan harga yang menunjukkan fluktuasi pasar dalam satu periode waktu ( volatilitas ) merupakan gambaran seberapa besar resiko yang akan dihadapipara pelaku ekonomi pada masa yang akan datang. Volatilitas dalam penelitian ini dibangun menggunakan modelAutoregressive Conditional Heteroskedasticit (ARCH). Tujuan dari penelitian ini adalah untuk menentukan volatilitas harga eceran dari beberapa komoditas pangan utama yaitu cabai rawit merah dan tomat apel di Kota Manado. Penelitian ini menggunakan data sekunder periode Januari 2013 - Desember 2016. Hasil penelitian menunjukkan bahwa model volatilitas untuk cabai rawit merah dan tomat apel adalah model $\mathrm{ARCH}(1)$

A B S T R A C T

The main food consumption such as red pepper and apple tomato has always been the spotlight for the society, this is due to the fixed price and always fluctuate in every period. The magnitude of price changes that indicate market fluctuations in a period of time (volatility) is a picture of how much risk will be faced by economic actors in the future. Volatility in this research was built using Autoregressive Conditional Heteroskedasticit (ARCH) model. The purpose of this study is to determine the retail price volatility of some major food commodities namely red chili and apple tomatoes in Manado City. This study uses secondary data from January 2013 to December 2016. The results showed that the volatility model for red cayenne and apple tomato was $\mathrm{ARCH}(1)$ model
\end{abstract}

KEYW OR D S

Red Chili

Apple Tomatoes

Volatility

AR-CH/GARCH
TERSEDIA ONLINE

01 Agustus 2018

\section{Pendahuluan}

Dalam beberapa tahun terakhir, resiko dan ketidakpastian yang dihadapi oleh konsumen maupun produsen akibat fluktuasi harga bahan pokok cenderung meningkat. Besaran perubahan harga yang menunjukkan fluktuasi pasar dalam satu periode waktu dinamakan volatilitas.Analisis volatilitas harga sangat diperlukan oleh para pelaku ekonomi karena hasil analisisnya dapat digunakan untuk pengambilan keputusan terkait masalah risiko usaha. Dampak yang timbul dari data yang volatilitasnya tinggi adalah peubah galat memiliki varian yang tidak konstan. Oleh karena itu, untuk memodelkan perilaku data dengan volatilitas tinggi dapat menggunakan model Autoregressive Conditional Heteroscedasticity (ARCH) (Engle, 2004).

Model Autoregressive Conditional Heteroscedastic (ARCH) diperkenalkan oleh Engle (1982) yang merupakan suatu model time series yang dapat mengakomodasi sifat heteroskedastik. Proses ARCH adalah proses dengan rataan (mean) nol, tak berkorelasi, variansi bersyarat (conditional) pada waktu lampau tidak konstan, sedangkan variansi tak-bersyarat (unconditional) adalah konstan (Nainggolan, 2009). Kemudian Bollerslev (1986) mengembangkan model ARCH menjadi model Generalized Autoregressive Conditional 
Heteroscedastic (GARCH). Engle (1982) telah berhasil melakukan penelitian tentang perkiraan varians dari inflasi United Kingdom dengan menggunakan model Autoregressive Conditional Heteroscedastic (ARCH) (Nainggolan, 2009).

Di Indonesia komoditas pangan yang fluktuasi harganya sering menjadi sorotan adalah beras, cabai, bawang merah, tomat, susu, daging, tepung terigu, gula pasir dan sebagainya.Kenaikan harga sembilan bahan pokok ini berentetan dengan kenaikan harga barang dan biaya hidup akibat kenaikan harga BBM, seperti kenaikan tarif angkutan, dan lainnya sehingga terjadi gejala heteroskedastisitas pada data time series yang menunjukan unsur volatilitas (Enders, 1995). Terkait dengan pola konsumsi pangan sebagian besar masyarakat golongan menengah ke bawah, yang menjadi perhatian pada penelitian ini adalah cabai rawit erah dan tomat apel di Kota Manado. Untuk meningkatkan efektivitas kebijakan dan program stabilisasi harga pangan dibutuhkan informasi yang lengkap mengenai perilaku harga komoditas yang bersangkutan. Konsep volatilitas berkaitan erat dengan risiko dan ketidakpastian yang dihadapi dalam pengambilan keputusan (Sumaryanto, 2009). Sumaryanto telah lebih dulu melakukan penelitian sembilan bahan pokok di Indonesia kemudian penulis akan meneliti dengan menggunakan data harga eceran komoditas pangan utama periode dari tahun 2013-2016 dari Kantor Dinas Perindustrian dan Perdagangan Daerah Sulawesi Utara. Berdasarkan uraian di atas, maka dalam penelitian ini akan dilakukan pengujian pada harga eceran cabai rawit merah dan tomat apel pada periode tahun 2013-2016.

\section{Metode Penelitian \\ Sumber Data}

Data yang digunakan merupakan data sekunder harga eceran komoditas pangan utama yaitu cabai rawit merah dan tomat apel periode mingguan selama empat tahun yaitu dari tahun 2013 sampai dengan 2016 dengan jumlah pengamatan sebanyak 209 minggu. Pada penelitian ini data bersumber dari Dinas Perindustrian Dan Perdagangan Daerah Provinsi Sulawesi Utara yang dikelola dari dua pasar yaitu pasar bersehati dan pasar Karombasan (pinasungkulan) dimana data diambil dari hari senin sampai dengan sabtu.

\section{Waktu dan Tempat Penelitian}

Penelitian ini sudah dilakukan pada bulan Desember 2017 sampai April 2018 di Laboratorium Komputer Dasar Fakultas Matematika dan IImu Pengetahuan Alam Universitas Sam Ratulangi Manado dan Kantor Dinas Perindustrian Dan Perdagangan Daerah Provinsi Sulawesi Utara sebagai tempat pengambilan data.

\section{Teknik Analisis Data}

Teknik analisis yang digunakan dalam mengaplikasikan model ARCH/GARCH pada penelitian ini menggunakan bantuan perangkat lunak komputer dengan urutan langkah sebagai berikut :

1. Pembuatan plot/grafik data harga eceran cabai rawit merah dan tomat apel.

2. Uji Stasioneritas Data

a. Uji Akar Unit (Unit Root Test)

b. Correlogram ACF dan PACF

c. Proses Diferensing

3. Identifikasi Model ARMA dan Penaksiran parameter

4. Uji Diagnosis Model ARMA

5. Identifikasi Model ARCH-GARCH (Varians)

a. Pengujian efek ARCH

b. Penentuan model ARCH-GARCH

6. Perhitungan nilai volatilitas harga

\section{Hasil dan Pembahasan}

\section{Plot Data Perkembangan Harga Eceran}

Berdasarkan plot data mingguan harga cabai rawit merah dan tomat apel di kota manado yang dianalisis dari awal januari 2013 sampai desember 2016 terlihat bahwa harga berfluktusasi setiap minggunya. Perkembangan harga eceran Cabai Rawit Merah dan tomat Apel periode awal Januari2013 sampai Desember 2016 dapat dilihat pada grafik yang disajikan pada grafik gambar 1 :

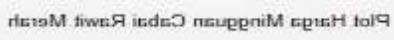

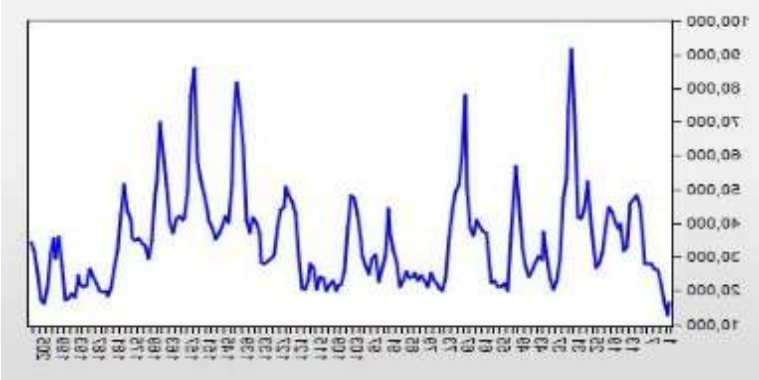

Gambar 1. Perkembangan harga eceran cabai rawit merah periode Januari 2013 Desember 2016.

Dari gambar 1 terlihat bahwa harga mingguan cabai rawit merah berkisar antara $\mathrm{Rp} 10.000,00$ hingga Rp 100.000,00. Fluktuasi pola data menggambarkan adanya fluktuasi harga yang secara keseluruhan memiliki kecenderungan harga yang naik turun. Harga terendah cabai rawit merah adalah Rp 16.714,00/kg yang dicapai pada minggu ke-1 yaitu pada bulan Januari 2013, kemudian harga tertinggi cabai rawit merah yaitu sebesar $\mathrm{Rp}$ $91.792,00 / \mathrm{kg}$ yang dicapai pada minggu ke-33 yaitu pada bulan Agustus 2013. Selanjutnya dari data ke-34 menurun kembali dan cenderung berfluktuasi sampai data ke-209 pada tahun 2016 . 


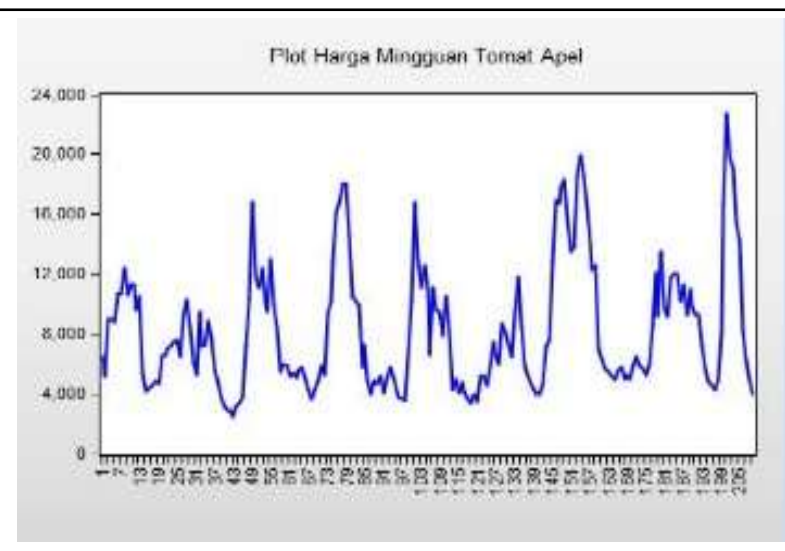

Gambar 2. Perkembangan harga eceran mingguan periode Januari 2013 - Desember 2016.

Perkembangan harga dari deret waktu berdasarkan gambar 2 dari plot data terlihat bahwa harga mingguan tomat apel berkisar antara Rp $2.000,00$ hingga Rp 24.000,00. Fluktuasi pola data menggambarkan adanya fluktuasi harga yang secara keseluruhan memiliki kecenderungan harga yang naik turun juga. Dimana harga terendah tomat apel yaitu Rp 2.500,00 per/kg yang dicapai pada minggu ke-43 yaitu pada bulan Oktober 2013, harga tertinggi tomat apel mencapai Rp 22.758,00 per/kg yang dicapai pada minggu ke-201 yaitu pada bulan November 2016.

Setelah melihat hasil plot dari data yang di analisis bahwa harga eceran yang cenderung naik turun atau tidak stabil dan akan dilanjutkan untuk menguji tingkat kestasioneran dari data.

\section{Identifikasi Model ARMA}

Uji akar unit (unit root test)

\section{a.Harga Eceran Cabai Rawit merah}

Tabel 1. Uji akar unit untuk harga eceran cabai rawit merah:

\section{Null Hypothesis: CABAl has a unit root}

Exogenous: Constant

Lag Length: 1 (Automatic - based on SIC, maxlag=14)

\begin{tabular}{lccc}
\hline \hline & t-Statistic & Prob.* \\
\hline \hline Augmented Dickey-Fuller test statistic & -6.261647 & 0.0000 \\
\hline Test critical values: $\quad$ 1\% level & -3.461938 & \\
& 5\% level & -2.875330 & \\
& 10\% level & -2.574198 & \\
\hline \hline
\end{tabular}

*MacKinnon (1996) one-sided p-values.

Hasil akar unit dapat dilihat dari nilai p-value berdasarkan uji hipotesis sebagai berikut:

Cabai Rawit Merah memiliki akar unit (data tidak stasioner)

Cabai Rawit Merah tidak memiliki akar unit (data stasioner)

$\alpha=0,05$

Maka apabila nilai $p$-value $>0,05$ maka terima

atau cabai rawit merah memiliki akar unit (data tidak stasioner), dan jika nilai P-value < 0,05 maka tolak atau cabai rawit merah tidak memiliki akar unit (data stasioner). Selain melihat dari uji hipotesis, uji akar unit juga dapat dilihat berdasarkan nilai ADF (Augmented Dickey-Fuller). Jika nilai ADF > nilai Critical Value MacKinon (1\% 5\%

10\%) maka dapat dikatakan terima yang artinya bahwa cabai rawit merah memiliki akar unit (data tidak stasioner). Jika nilai ADF < nilai Critical Value

MacKinon (1\% 5\% 10\%) dikatakan tolak artinya cabai rawit merah tidak memiliki akar unit (data stasioner).

Berdasarkan hasil output pada table 1dari data cabai rawit merah menunjukkan bahwa nilai $p$-value $=(0,0000)<0,05$ dan kemudian nilai ADF ($6,261467)<$ nilai Critical Value Mackinon (5\%) maka disebut tolak yang artinya cabai rawit merah tidak memiliki akar unit (data stasioner).

\section{c. Harga Eceran Tomat Apel}

Tabel 2 . Uji akar unit untuk Tomat Apel:

$$
\begin{aligned}
& \text { Null Hypothesis: TOMAT has a unit root } \\
& \text { Exogenous: Constant } \\
& \text { Lag Length: } 1 \text { (Automatic - based on SIC, maxlag=14) }
\end{aligned}
$$

\begin{tabular}{lccc}
\hline \hline & t-Statistic & Prob* \\
\hline \hline Augmented Dickey-Fuller test statistic & -4.434398 & 0.0003 \\
\hline Test critical values: $\quad$ 1\% level & -3.461938 & \\
& 5\% level & -2.875330 & \\
& 10\% level & -2.574198 & \\
\hline \hline
\end{tabular}

*Mackinnon (1996) one-sided p-values.

Berdasarkan hasil output pada table 2 tomat apel dapat dilihat bahwa nilai $p$-value $=0,0003<$ 0,05, maka disebut tolak yang artinya bawang merah tidak memiliki akar unit atau data tersebut sudah stasioner. Kemudian apabila dilihat dari nilai ADF (-4.434398) yang nilainya < dari nilai Critical Value MacKinon (5\%) maka disebut tolak , artinya bahwa data tidak memiliki akar unit atau data sudah stasioner.

Dari hasil uji akar unit dapat dilihat bahwa ketiga data tidak memiliki akar unit (data stasioner) dengan melihat nilai $p$-value $<0,05$, sehinga tahapan selanjutnya dapat di lanjutkan dengan menampilkan coleogram ACF dan PACF untuk membentuk model ARIMA ( Natasya, 2017).

\section{Coleogram ACF dan PACF}

\section{a. Harga Eceran Cabai Rawit Merah}

Langkah berikut setelah melakukan uji akar unit kita dapat melihat coleogram ACF dan PACF dari data pada gambar 3 : 


\begin{tabular}{|c|c|c|c|c|c|c|}
\hline Autocorrelation & Partial Conreiation & & $A C$ & PAC & Q-stat & Prob \\
\hline $1 \longmapsto$ & : & 1 & 0.046 & 0.046 & 154.73 & 0.000 \\
\hline i业 & 1 & $\frac{1}{2}$ & 0598 & -0.414 & 22791 & 0.000 \\
\hline $1=$ & isi & 3 & 0.385 & 0.005 & 250.60 & 0.000 \\
\hline 洰 & 1, & 4 & 0.240 & 0.009 & 272.09 & 0.000 \\
\hline 淌 & ii, & 5 & 0.154 & 0.014 & 27721 & 0000 \\
\hline 15 & $i 1$ & 8 & 0.099 & -0.024 & 27234 & 0000 \\
\hline ifi. & 11 & 7 & 0.062 & 0.004 & 280.10 & 0.000 \\
\hline iff. & is & B & 0.057 & 0.084 & 280.90 & 0.000 \\
\hline in & i. & 9 & 0.078 & 0.035 & 282.25 & 0.000 \\
\hline 15 & ifi. & 10 & 0112 & 0.047 & 28504 & 0.000 \\
\hline ig & 7 & 11 & 0.137 & .0002 & 280.22 & 0000 \\
\hline 泊 & ini & 12 & 0.152 & 0.040 & 29441 & 0.000 \\
\hline 淌 & ifii & 13 & 0.169 & 0.063 & 300.86 & 0.000 \\
\hline 淌 & in & 14 & 0.170 & -0.017 & 307.09 & 0.000 \\
\hline 垖 & ili & 15 & 0.172 & 0.020 & 314.64 & 0.000 \\
\hline 治 & i. & 16 & 0.162 & 0.022 & 320.65 & 0.000 \\
\hline 吕 & 1, & 17 & 0.145 & -0.002 & 325.45 & 0.000 \\
\hline 15 & iti & 18 & 0.126 & 0.010 & 329.04 & 0.000 \\
\hline 15 & ifi & 19 & 0109 & 0.014 & 331.70 & 0000 \\
\hline i & ifi & 20 & 0004 & -0.047 & 333.44 & 0000 \\
\hline ifi & 7, & 21 & 0055 & 0.001 & 334.14 & 0,000 \\
\hline ifi & $i 1$ & 22 & 0.033 & 0.006 & 334.40 & 0.000 \\
\hline ifi, & ifi & 23 & 0.004 & -0.000 & 334.40 & 0.000 \\
\hline ifi: & ti & 24 & -0.043 & -0.090 & $334 \mathrm{ad}$ & 0000 \\
\hline (1) & in & 25 & -0.097 & -0.044 & 337.11 & 0.000 \\
\hline
\end{tabular}

Gambar 3. Coleogram ACF dan PACF harga eceran cabai rawit merah

Dapat dilihat berdasarkan gambar 3 grafik ACF menunjukkan penurunan secara perlahan dari lag-1 sampai lag-5 yang kemudian memotong kembali pada lag 11 sampai lag-17 kemudian pada PACF terputus (cut-off) pada lag-2 akan tetapi pada pengujian ADF yang dilakukan sebelumnya telah diketahui bahwa harga cabai rawit merah sudah stasioner sehingga tidak perlu dilakukan diffrensing.

\section{b. Harga Eceran Tomat Apel}

\begin{tabular}{|c|c|c|c|c|c|c|}
\hline " & $=$ & 1 & 0.864 & 0.864 & 15825 & 0.000 \\
\hline 足 & 口! & 2 & 0.699 & -0.186 & 25243 & 0.000 \\
\hline י & d. & 3 & 0.526 & -0.122 & 32195 & 0.000 \\
\hline 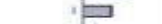 & ㄷ. & 4 & 0.340 & -0.161 & 346.53 & 0.000 \\
\hline 'p & त. & 5 & 0.169 & -0.069 & 35271 & 0.000 \\
\hline of & 17. & 6 & 0.034 & -0.003 & 35295 & 0.000 \\
\hline tis & wi & 7 & -0.055 & 0.042 & 353.52 & 0.000 \\
\hline di & fi. & a & -0.131 & -0.094 & 35740 & 0.000 \\
\hline 무: & if. & 9. & -0.183 & -0.045 & 36499 & 0.000 \\
\hline ㅂ. ‥ & if & 10 & -0.221 & -0.048 & 37580 & 0.000 \\
\hline 믐 & id. & & -0.247 & -0.051 & 38939 & 0.000 \\
\hline 日。 & in. & 12. & -0.287 & -0.050 & 40532 & 0.000 \\
\hline 三. & i. & 13 & -0.282 & -0.057 & 423.19 & 0.000 \\
\hline 三. & 1.1. & 14 & -0.280 & -0.009 & 440.92 & 0.000 \\
\hline 目。 & if. & 15. & -0.270 & -0.029 & 457.45 & 0.000 \\
\hline 무 & 1 . & 15 & -0.247 & -0.004 & 47136 & 0.000 \\
\hline 目: & i. & 17 & -0.218 & -0.038 & 48227 & 0.000 \\
\hline d: & at & 13. & -0.172 & 0.035 & 48910 & 0.000 \\
\hline cis & s & 19. & -0.102 & 0.075 & 491.54 & 0.000 \\
\hline i. & if. & 20. & -0.027 & 0.034 & 49171 & 0.000 \\
\hline in & if & 21 & 0.062 & 0.087 & 492.62 & 0.000 \\
\hline if & $\sqrt{1}$ & 22 & 0.133 & -0.011 & 497.15 & 0.000 \\
\hline 的 & it & 23 & 0.190 & -0.020 & 505.69 & 0.000 \\
\hline 吕 & ib. & 24 & 0228 & 0.037 & 51805 & 0.000 \\
\hline 泊 & i. & 25 & 0.233 & -0.041 & 531.10 & 0.000 \\
\hline
\end{tabular}

Gambar 4. Coleogram ACF dan PACF harga eceran tomat apel

Berdasarkan gambar 4 coleogram untuk harga eceran tomat apel menunjukkan nilai koefisien ACF bergerak menurun secara perlahan yaitu dari lag-1 sampai kepada lag-lag yang selanjutnya dan PACF yang terputus pada lag- 2 yang kemudian setiap lagnya yang cenderung mendekati nol.

Setelah mendeteksi masalah kestasioneran dari data maka selanjutnya yaitu identifikasi model ARMA untuk data harga eceran mingguan. Dengan melihat coleogram dari ACF dan PACF dapat dibentuk model ARIMA berdasarkan cuts off pada lag $(p, q)$. Semua model rataan pada penelitian adalah model ARMA karena semua data yang dianalisis merupakan data yang stasioner tanpa difrensing. Penentuan model ARMA dilakukan berdasarkan pola ACF dan PACF pada correlogram untuk menentukan orde AR (p) dan orde MA (q). Dari model ARMA yang terbentuk, dipilih model ARMA terbaik. Tetapi karena pada pengujian ini model yang memiliki nilai AIC dan SIC terendah tidak memenuhi dalam pengujian kelayakan model yaitu pada Uji ARCH LM sehingga dilakukan kembali pemilihan model yang layak dan model ARMA terbaik yang didapat untuk masing-masing analisis disajikan pada Tabel 4.

Tabel 3. Model ARMA terbaik harga eceran periode mingguan

\begin{tabular}{|l|l|}
\hline Uraian & Model ARMA terbaik \\
\hline Cabai rawit merah & ARMA $(1,2)$ \\
\hline Tomat apel & ARMA $(1,4)$ \\
\hline
\end{tabular}

Berdasarkan tabel 3 Model ARMA terbaik cabai rawit merah yaitu ARMA $(1,2)$ dan tomat apel adalah $\operatorname{ARMA}(1,4)$, kemudian model terpilih akan di tafsir parameternya.

\section{Penaksiran Parameter}

Model yang dipilih akan ditaksir parameternya pada model ARMA $(p, q)$ masing-masing harga eceran berdasarkan hasil dari estimasi pada output. Penaksiran parameter untuk model cabai rawit merah, bawang merah, dan tomat apel yang diolah dengan menggunakan software yaitu eviews diperoleh hasil sebagai barikut:

a. $\operatorname{ARMA}(1,2)$ untuk cabai rawit merah

$z_{t}=35614,71+0,678352 z_{t-1}+0,553435 \varepsilon_{t-1}+0,155790 \varepsilon_{t-2}+\varepsilon_{t}$

b. $\operatorname{ARMA}(1,4)$ untuk tomat apel

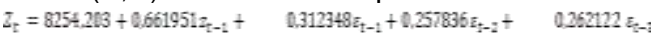
$+0,150054 s_{-4}+z_{3}$

Dari model terpilih kemudian akan diuji kembali apakah sudah menghasilkan residual yang random (white noise) sehingga model tersebut merupakan model yang sudah baik yang mampu menjelaskan data dengan baik.

\section{Uji Diagnostik Model ARMA}

Berikut pengujian white noise dari data berdasarkan hipotesis:

: vektor residual memenuhi asumsi white noise : vektor residual tidak memenuhi asumsi white noise $\alpha=0,05$

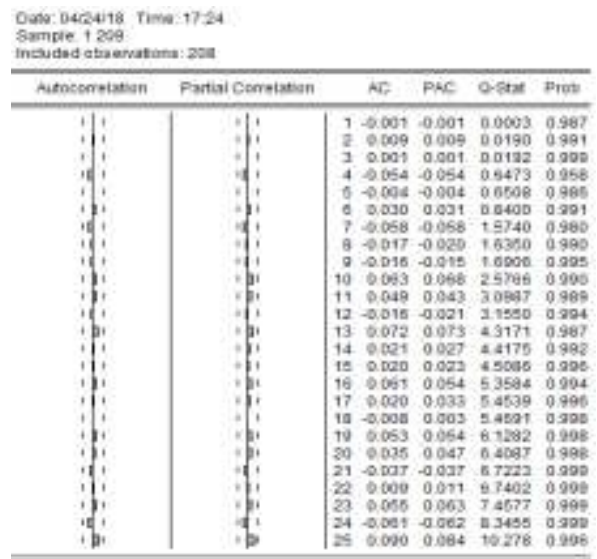

Gambar 5. Correlogram white noise cabai rawit merah 


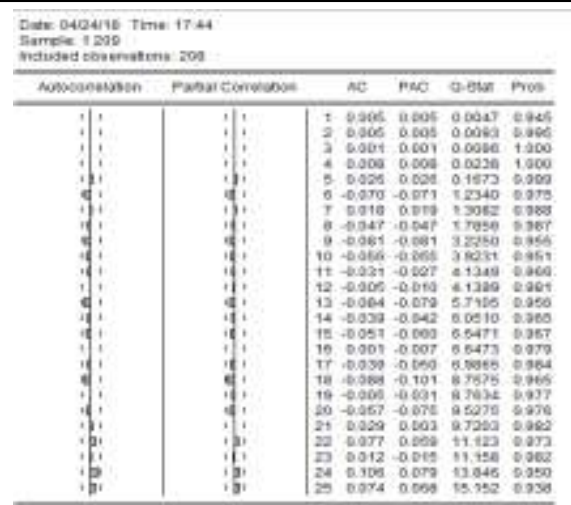

Gambar 6. Correlogram white noise tomat apel

Berdasarkan gambar diatas dapat dilihatbahwa masing-masing lag memiliki nilai probabilitas yang lebih besar dari $\quad \alpha=$ sehingga tolak dan dapat dikatakan bahwa setiap data memnuhi asumsi white noise, maka dapat disimpulkan bahwa residual yang diestimasi dari model $\operatorname{ARMA}(1,2)$, dan ARMA $(1,4)$ merupakan residual yang sudah white noise. Dengan menyelesaikan langkah ini maka model akan di identifikasi untuk menentukan model ARCH terbaik.

\section{Identifikasi Model ARCH}

Dari model ARMA terbaik yang telah didapatkan dari tahap sebelumnya kemudian dilakukan kembali pengujian efek ARCH dan selanjutnya melakukan penentuan model ARCH/GARCH berdasarkan coleogram residual kuadrat.

Tabel 4. Model ARCH terbaik dari harga eceran

\begin{tabular}{|c|c|}
\hline Uraian & Model GARCH terbaik \\
\hline Cabai rawit merah & ARCH (1) \\
\hline Tomat apel & ARCH (1) \\
\hline
\end{tabular}

Pada tabel 4dapat di dilihat bahwa model $\mathrm{ARCH}$ terbaik untuk cabai rawit merah adalah $\mathrm{ARCH}$ (1),dan pada tomat apel adalah ARCH (1), kemudian langkah yang sangat penting dalam menentukan model adalah dengan mengevaluasi model tersebut apakah model memang sudak cukup baik dan dapat digunakan dalam menghitung volatilitas harga eceran dari data yang di analisa.

\section{Evaluasi Model}

Evaluasi model dilakukan dengan memeriksa kecukupan model sehingga model yang diperoleh cukup memadai. Jika model tidak memadai, maka kembali ke tahap identifikasi untuk mendapatkan model yang lebih baik. Diagnosis model dilakukan dengan menganalisis residual yang telah distandardisasi, dengan melakukan pengujian efek $\mathrm{ARCH}$ residual menggunakan uji ARCH LM. Kemudian untuk menentukan bahwa model sudah baik adalah dengan melihat kembali apakah nilai $p$ value $>0,05$ sehingga model tersebut dapat dikatakan sudah cukup baik dan untuk evaluasi untuk model ARCH/GARCH dapat dilihat berdasarkan output berikut,
Tabel 5. Uji ARCH-LM residual pada cabai rawit merah:

Heteroskedasticity Test: ARCH

\begin{tabular}{llll}
\hline \hline F-statistic & 0.437804 & Prob. $F(1,205)$ & 0.5089 \\
Obs*R-squared & 0.441133 & Prob. Chi-Square(1) & 0.5066 \\
\hline
\end{tabular}

Tabel 6. Uji ARCH-LM residual pada tomat apel: Heteroskedasticity Test: ARCH

\begin{tabular}{llll}
\hline \hline F-statistic & 0.016576 & Prob. F $(1,205)$ & 0.8977 \\
Obs*R-squared & 0.016736 & Prob. Chi-Square(1) & 0.8971 \\
\hline \hline
\end{tabular}

Pada table 5 dan 6 dapat dilihat bahwa hasil output pada data yang dianalisa dengan menggunakan uji ARCH-LM terlihat bahwa nilai $\mathrm{p}$ value > 0,05 dan ini membuktikan bahwa model ARMA terpilih sudah merupakan model yang cukup baik karena data sudah homoskedastik (efek arch tidak ada), sehingga analisis ARCH/GARCH dapat dilanjutkan dengan menggunakan rumus perhitungan volatilitas.

\section{Perhitungan Nilai Volatilitas}

Hasil analisis ARCH/GARCH terhadap harga eceran komoditas pangan utama menghasilkan model terbaik untuk estimasi volatilitas harga cabai rawit merah yaitu model ARCH (1). Model tersebut memberikan informasi tentang tingkat pergerakan harga pada periode Januari 2013 sampai Desember 2016. Persamaan model ragam harga cabai rawit merah dituliskan sebagai berikut:

$$
h_{\mathrm{t}}=16734498_{s} 1774+0,988 \varepsilon_{t-1}^{2}
$$

Volatilitas Cabai Rawit Merah

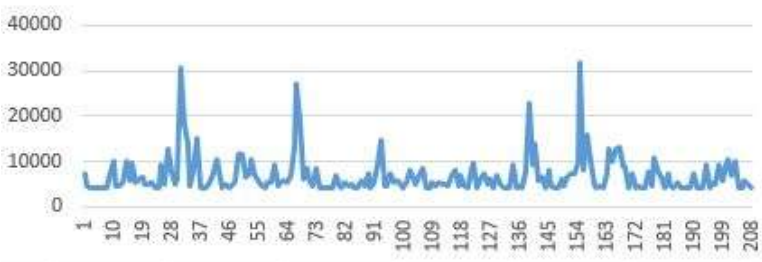

Gambar 7. Volatilitas harga eceran mingguan cabai rawit merah periode periode Januari 2013 -

Desember 2016.

Nilai volatilitas harga cabai rawit merah di Kota manado dapat dilihat bahwa pergerakan fluktuasinya selalu yang naik turun, dan pergerakan nilai tertinggi terjadi pada periode tertentu yaitu dapat dilihat pada (gambar 7), terdapat diantara minggu ke-28 sampai minggu ke-37 dan yang terjadi kembali dengan nilai yang lebih tinggi yaitu diantara minggu ke-154 sampai minggu ke-163.

Volatilitas harga eceran yang selanjutnya adalah harga eceran tomat apel di Kota manado disajikan pada gambar 8 . Dengan persamaan model ragam sebagai berikut:

$$
h_{t}=1765920,783+0,768 \varepsilon_{t-1}^{2}
$$




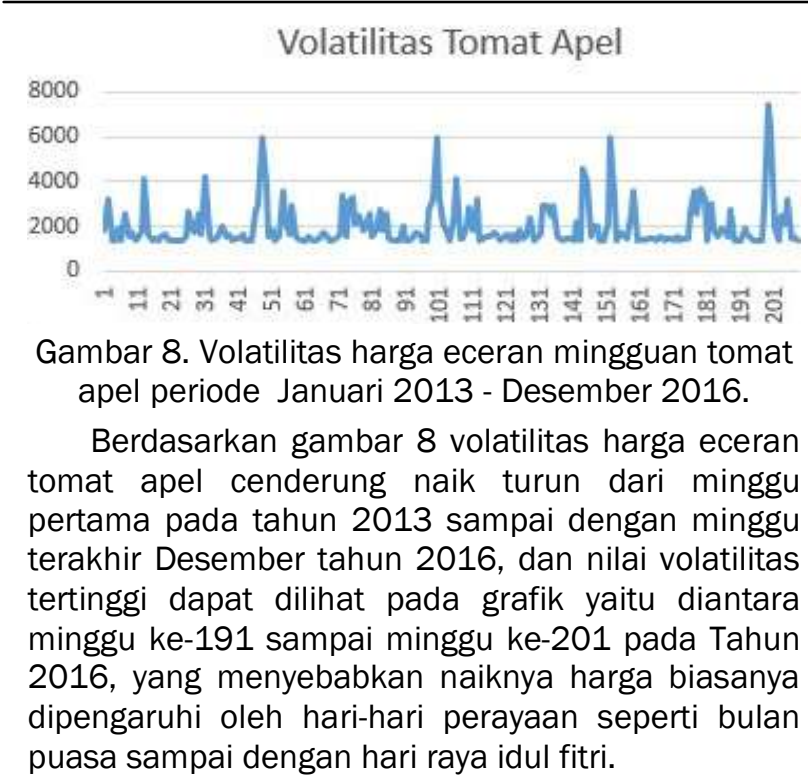

\section{Kesimpulan}

Volatilitas harga eceran cabai rawit merah dantomat apel di Kota manado bergerak dengan fluktuasi yang tidak stabil, karena pada mingguminggu tertentu terjadi fluktuasi yang tinggi yang menyebabkan harga tersebut tidak stabil. Model volatilitasyang terpilin untuk cabai rawit merah adalah ARCH (1) yaitu, $h_{\mathrm{t}}=16734498,1774+0,98 \mathrm{~s}$, dan model volatilitas Tomat apel terdapat pada ARCH (1) yaitu,

$$
h_{\mathrm{t}}=1765920,783+0,76 \mathrm{\varepsilon} \text {. }
$$

\section{Daftar Pustaka}

Bollerslev, T. 1986. Generalized Autoregressive Conditional Heteroskedasticity. Journal of Econometrics.31: 307-327.

Enders. 1995. Applied Econometric Time Series 2nd Edition, John Wiley \& Sons, Inc. New York.

Engle, R. F. 1982. Autoregressive Conditional Heteroscedasticity with Estimates of ,the Variance of United Kingdom Inflation. Journal of Econometrica. 50: 987-1008.

Engle, R. F. 2004. Risk and Volatility : econometric models and financial practice. The American Ekonomi Review, 94: 405-420.

Nainggolan, N. 2009. Model Time Series Heteroskedastik. Unpad Press. Bandung.

Natasya, B. Y., N, Nainggolan, dan Hanny, A. H. K. 2017. Penerapan Model ARIMA-GARCH Untuk Memprediksi Harga Saham Bank BRI. Jurnal MIPA Unsrat Online. 6(2): 92-96

Sumaryanto. 2009. Analisis volatilitas harga eceran beberapa komoditas pangan utama dengan model ARCH/GARCH. Jurnal Agro Ekonomi, 27: 135-163. 